\title{
Patogenicidade de fungos associados às sementes $e$ plântulas de amendoim cv. Tatu
}

\section{Pathogenicity of seed-borne and seedling fungi of groundnut cv. Tatu}

\author{
Nair Mieko Takaki Bellettini ${ }^{1}$; Romeu Munashi Endo ${ }^{2}$; \\ Édison Miglioranza ${ }^{2}$; Débora Cristina Santiago ${ }^{2 *}$
}

Resumo

Sementes e plântulas de amendoim (Arachis hypogaea) cv. Tatu foram avaliadas em condições de laboratório e casa de vegetação com o objetivo de detectar e identificar a presença de fungos patogênicos associados às sementes, além de determinar a patogenicidade e os danos por eles causados. Os fungos detectados foram Aspergillus niger, Fusarium oxysporum, Cercospora arachidicola, Rhizopus sp., Penicillium sp., Cladosporium sp. e Phoma sp.. Os fungos mais freqüentes foram A. niger e Penicillium sp.. Estes fungos foram transmitidos através das sementes e causaram tombamento de pré e pósemergência nas plântulas.

Palavras-chave: Tombamento, podridão, doenças de plantas, Arachis hypogaea

\begin{abstract}
Seeds and seedlings of groundnut (Arachis hypogaea) cv. Tatu were investigated under laboratory and green house conditions to detect and identify any seed-borne pathogenic fungi present, besides determining the pathogenicity and the seed damages. The fungi detected were Aspergillus niger, Fusarium oxysporum, Cercospora arachidicola, Rhizopus sp., Penicillium sp., Cladosporium sp. and Phoma sp.. The most frequently isolated fungi were Aspergillus niger and Penicillium sp.. These fungi were transmitted by seeds and caused damping-off before and after seedling emergence.
\end{abstract}

Key words: Damping-off, rot, plant disease, Arachis hypogaea

\section{Introdução}

O amendoim cultivado (Arachis hypogaea L.) compreende as subespécies hypogaea e fastigiata (KRAPOVICKAS; GREGORY, 1994). Com a expansão do seu cultivo, as cultivares de fastigiata passaram a ser vulgarmente conhecidas por grupos Valência e Spanish, de porte ereto, precoce e são as mais disseminadas nas diversas regiões brasileiras onde predominam pequenos produtores (GODOY et al., 1999). Em sistemas de produção em que a colheita é manual ou semi-mecanizada, as plantas de porte ereto são as mais indicadas. A precocidade é requerida nas regiões onde o amendoim é cultivado em sucessão com a cana-de-açúcar, e é um atributo vantajoso no controle de doenças ou de outros fatores de estresse (MORAES et al., 1994).

\footnotetext{
1 Professora Doutora do Curso de Graduação em Agronomia, Departamento de Fitotecnia, Faculdades "Luiz Meneghel” de Bandeirantes. Rodovia BR 369 - Km 54 - Caixa Postal: 261 - CEP 86360-000 Bandeirantes - PR.

2 Engenheiros Agrônomos, Doutores, Professores, Departamento de Agronomia, CCA, Universidade Estadual de Londrina, Campus Universitário, C.P. 6001, CEP 86051-990, Londrina, PR. *Endereço para correspondência.
} 
A cultura de amendoim é afetada por várias doenças, algumas das quais, de grande importância econômica, a exemplo das manchas foliares causadas por Cercospora arachidicola Hori e Cercosporidium personatum (BERK. \& CURT.) Deighton, consideradas as mais prejudiciais em todas as áreas de produção do Brasil (MORAES et al., 1988; SOARES; LIMA, 1991). A ocorrência de outras doenças como podridões de sementes, murchas e tombamentos também é freqüente. Em sementes de amendoim cerca de 150 espécies de fungos foram identificadas, sendo muitas delas responsáveis por perdas elevadas na cultura (JOFFE, 1969; HANLIN, 1973)

Neergaard (1979) afirmou que em média 15\% das perdas na cultura eram causadas por doenças decorrentes de microrganismos transmitidos através das sementes. Aspergillus niger é um dos principais responsáveis por podridões de colo e tombamento de pré-emergência em plântulas de amendoim. Ele sobrevive saprofiticamente em sementes e no solo. Quando seu inóculo é transportado via sementes pode apodrecê-las durante a germinação ou causar podridão no colo das plântulas (LIMA; ARAÚJO, 1999). Segundo Cook (1981) várias espécies de Fusarium, como F. moniliforme, F. oxysporum, $F$. roseum, F. solani, F. phaseoli e F. tricinctum, podem causar sintomas de murcha, podridão de sementes, de vagens, de raízes e de plântulas de amendoim.

Moraes e Mariotto (1985), mediante diagnóstico da patologia de sementes de amendoim, destacaram a necessidade da realização de pesquisas direcionadas à detecção de microrganismos e à importância destes na sanidade das sementes e da cultura, principalmente se considerarmos que a qualidade das sementes é uma das principais restrições do plantio de amendoim no Brasil, e mesmo porque o custo da semente é um dos componentes que mais oneram o cultivo.

Buscando contribuir nesse campo de conhecimento, o presente trabalho teve como objetivo detectar a presença, determinar a patogenicidade de fungos e os danos por eles causados às sementes e plântulas de amendoim.

\section{Material e Métodos}

O trabalho foi conduzido no laboratório de Fitopatologia pertencente a Universidade Estadual de Londrina. Foram avaliadas sementes de amendoim cv. Tatu, produzidas na safra 2002/2003, na área experimental da Faculdade "Luiz Meneghel" em Bandeirantes/ PR, onde tradicionalmente se cultiva amendoim.

\section{Análise Sanitária e Fisiológica de Sementes}

Por ocasião da colheita, as vagens foram lavadas em água, desinfestadas superficialmente com hipoclorito de sódio (2,0\%), durante um minuto, e após enxaguadas duas vezes em água destilada esterilizada. Após procedeu-se a retirada das sementes das vagens com a película intacta e a separação em dois lotes com 200 sementes cada. Um dos lotes foi submetido à assepsia com hipoclorito de sódio de forma idêntica à empregada para vagens. A sanidade das sementes de cada lote foi determinada utilizando-se o método do papel de filtro ("Blotter test"), e em cada gerbox foram dispostas 20 sementes em número de 10 repetições. A incubação, durante oito dias, foi em câmara do tipo B.O.D. com alternância de 12 horas de luz. Após procedeu-se o exame das sementes com o auxílio de microscópio estereoscópico e a identificação dos microrganismos foi realizada com base nas características de suas estruturas e em literatura pertinente. Os fungos presentes foram isolados e cultivados em meio de cultura batata-dextrose-ágar (BDA) para confirmação da identificação. Os dados obtidos de incidência de fungos nas sementes avaliadas foram expressos em percentuais.

Paralelamente, foi efetuada a análise da qualidade fisiológica das sementes por meio da determinação dos percentuais de germinação de sementes com e sem assepsia em vermiculita e em rolos de papel, 
conforme metodologia descrita por Brasil (1992), tendo sido avaliadas 200 sementes por tratamento distribuídas em quatro repetições.

\section{Testes de Patogenicidade}

Os fungos freqüentemente associados às sementes, Aspergillus niger, Cercospora arachidicola e Fusarium oxysporum foram avaliados quanto a patogenicidade na emergência (sementes) e na pós-emergência (plântulas). Antes da inoculação com os fungos, as sementes foram desinfestadas superficialmente de maneira idêntica à descrita anteriormente e, em seguida, lavadas duas vezes com água destilada e esterilizada. O delineamento experimental foi inteiramente casualizado, com cinco tratamentos (A. niger, F. oxysporum, $C$. arachidicola imersão, $C$. arachidicola deposição e testemunha não inoculada) e 20 repetições de cinco plântulas por vaso, totalizando 100 plântulas por tratamento. Como testemunhas foram utilizadas 100 sementes imersas apenas em água destilada esterilizada.

Para inoculação, os fungos foram multiplicados em meio de cultura BDA em placas de Petri e incubados durante oito dias à temperatura de $27^{\circ} \pm$ $2^{\circ} \mathrm{C}$. Decorrido o período de crescimento dos fungos, 400 sementes (20 repetições com 20 sementes) foram depositadas na superfície das colônias onde permaneceram durante 12 horas. Após, procedeuse a semeadura em vasos de plástico, com capacidade para 1,5 L, contendo vermiculita esterilizada umedecida, e após mantidos em ambiente de casa-de-vegetação. A inoculação das sementes com o fungo $C$. arachidicola foi realizada por meio da disposição das sementes sobre as colônias durante 12 horas e também por imersão em suspensão de $10^{5}$ esporos do microrganismo, durante cinco minutos, imediatamente antes da semeadura.

Aos 10 e 20 dias da semeadura, procedeu-se a contagem das sementes germinadas, não germinadas e com presença de estruturas de fungos em sua superfície. E, aos 60 dias avaliou-se a patogenicidade de fungos inoculados por meio da determinação da altura e comprimento de raízes das plântulas emergidas e desenvolvidas.

Para avaliar a patogenicidade dos fungos isolados de sementes na pós-emergência, procedeu-se a inoculação de plântulas com 15 dias de idade em vasos plásticos com capacidade para 1,5 L, contendo vermiculita esterilizada, através da deposição de 25 $\mathrm{mL}$ da suspensão de esporos $\left(10^{5}\right)$ de $A$. niger, $F$. oxysporum e $C$. arachidicola, no substrato, ao redor de cada plântula e, nas plântulas utilizadas como testemunha foi utilizada apenas água destilada esterilizada. O delineamento experimental foi inteiramente casualizado com 100 plântulas (uma plântula por vaso) por tratamento (fungos e testemunha). Aos 45 dias da inoculação, procedeuse a avaliação por meio de visualização dos sintomas e cálculo dos percentuais de plântulas doentes.

\section{Resultados e Discussão}

\section{Análise Sanitária e Fisiológica de Sementes}

Independente da assepsia prévia das sementes, foram detectadas as presenças dos fungos $A$. niger, F. oxysporum, C. arachidicola, Rhizopus sp., Penicillium sp., Cladosporium sp. e Phoma sp. (Tabela 1), alguns com grande importância para a cultura do amendoim e outras culturas. Os mais freqüentes foram A. niger e Penicillium sp., considerados fungos de armazenamento e produtores de micotoxinas tóxicas ao homem. Também agentes causais de tombamento e podridões de acordo com Lima e Araújo (1999).

Para as sementes submetidas à assepsia com hipoclorito de sódio (2,0\%), o percentual de microrganismos encontrados foi menor (Tabela 1), indicando que grande parte dos microrganismos está associado externamente às sementes e, podendo mesmo ser contaminantes durante o processo de arranquio e debulha das vagens de amendoim. 
Tabela 1. Fungos associados à sementes de amendoim cv. Tatu. "Blotter Test". Londrina, PR.

\begin{tabular}{|c|c|c|c|}
\hline \multirow[t]{2}{*}{ Microrganismos } & \multicolumn{3}{|c|}{$\begin{array}{c}\text { Sementes infectadas e/ou contaminadas } \\
(\%)\end{array}$} \\
\hline & Com assepsia & Sem assepsia & CV (\%) assepsia \\
\hline Aspergillus niger & $77,45 \mathrm{~A} \mathrm{a}^{1}$ & $83,50 \mathrm{~A} \mathrm{a}$ & 12,17 \\
\hline Fusarium oxysporum & $10,20 \mathrm{D} \mathrm{b}$ & $36,70 \mathrm{BC} \mathrm{a}$ & 31,01 \\
\hline Cercospora arachidicola & $12,00 \mathrm{CD} b$ & $31,00 \mathrm{C} \mathrm{a}$ & 26,93 \\
\hline Rhizopus sp. & $22,90 \mathrm{C} \mathrm{b}$ & $39,00 \mathrm{BC} \mathrm{a}$ & 57,55 \\
\hline Penicillium sp. & $59,00 \mathrm{~B} \mathrm{~b}$ & $82,30 \mathrm{~A} \mathrm{a}$ & 14,83 \\
\hline Cladosporium sp. & $23,90 \mathrm{C} \mathrm{b}$ & $42,40 \mathrm{~B} \mathrm{a}$ & 34,69 \\
\hline Phoma sp. & $09,20 \mathrm{D} \mathrm{b}$ & $11,90 \mathrm{D} \mathrm{a}$ & 38,87 \\
\hline $\mathrm{CV}(\%)$ fungo & 42,49 & 25,13 & \\
\hline
\end{tabular}

${ }^{1}$ Médias seguidas de letras iguais, maiúsculas nas colunas e minúsculas nas linhas, não diferem entre si, pelo teste de Tukey no nível de 5\% de probabilidade.

A qualidade fisiológica das sementes de amendoim, previamente submetidas ou não a assepsia com hipoclorito de sódio, foi determinada por meio da contagem de sementes germinadas nos substratos vermiculita e em rolo de papel. O percentual de germinação das sementes foi maior no substrato rolo de papel, provavelmente devido às condições de temperatura e umidade necessárias à germinação serem melhores. Ficou evidente o efeito positivo da assepsia. O maior percentual de germinação foi obtido com sementes desinfetadas em comparação com as não desinfetadas (Figura 1), o que mostra o efeito prejudicial dos fungos associados mesmo externamente às sementes. Segundo Araújo e Rossetto (2003), a contaminação superficial por fungos dificulta a avaliação da qualidade fisiológica e sanitária de sementes, e a assepsia com hipoclorito de sódio diminui ou elimina a contaminação favorecendo a germinação das sementes, o que fortalece os resultados obtidos no presente estudo.

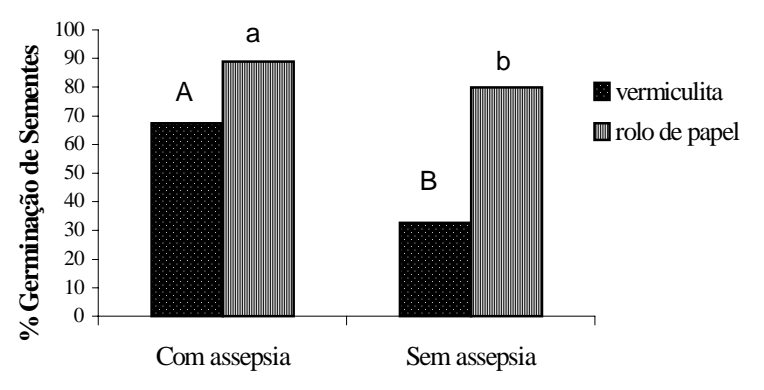

Figura 1. Germinação de sementes de amendoim cv. Tatu, submetida e não a assepsia, em vermiculita e rolo de papel.

\section{Teste de Patogenicidade}

A patogenicidade dos fungos associados às sementes, determinada pela sua inoculação nas sementes e plântulas, foi comprovada pelos sintomas de tombamentos observados na pré e pósemergência. $\mathrm{O}$ A. niger causou tombamento em pré e pós-emergência, ou seja, doença nas plantas inoculadas por meio de sementes bem como de plântulas. Quando o fungo foi inoculado nas sementes, ao quinto dia da inoculação, foi observada a podridão em $65 \%$ destas (Figura 2), as quais encontravam-se completamente recobertas por densa massa escura constituída pelas estruturas do patógeno. Em 61\% das plântulas inoculadas (Figura 3), observou-se podridão do colo e murcha com conseqüente morte das mesmas.

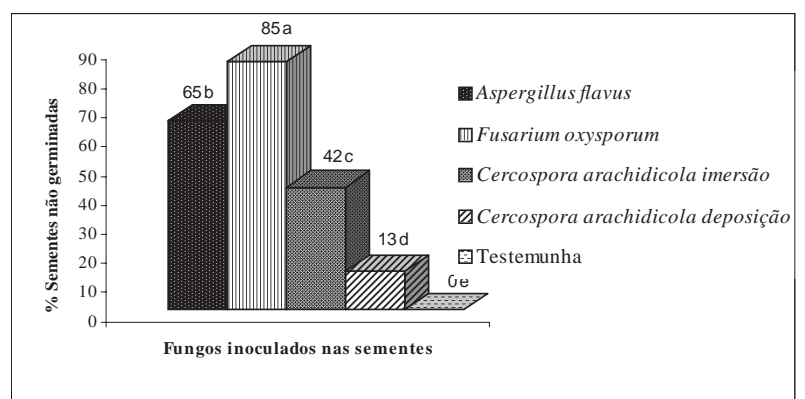

Figura 2. Sementes de amendoim cv. Tatu, inoculadas com fungos e não germinadas.

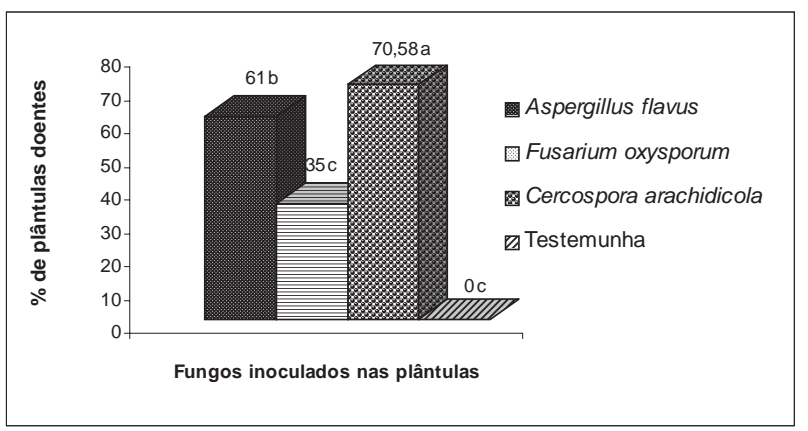

Figura 3. Plântulas de amendoim cv. Tatu inoculadas com fungos afetadas por podridão do colo ou mortas.

Pesquisadores têm evidenciado a importância do A. niger como responsável pela podridão de colo em plântulas (JACKSON, 1962; MORAES, 1979; MORAES, 1980; COOK, 1981; WEISS, 1983; 
LIMA; ARAÚJO, 1999) e redutor da germinação das sementes de amendoim (NAKAMURA; NISHIMURA, 1974; LIMA; ARAÚJO, 1999). Segundo Gibson (1953), a patogenicidade desse fungo deve-se a produção de ácido oxálico pelo patógeno, o que, possivelmente seja uma condição necessária à invasão do mesmo na região do hipocótilo das plântulas de amendoim.

Fusarium oxysporum causou tombamento na pré e pós-emergência. Nas sementes causou podridão em cerca de $85 \%$ destas e afetou a germinação (Figura 2). Quando inoculado nas plântulas, 35\% destas tornaram-se doentes e apresentaram lesões na região do colo e raízes (Figura 3). Segundo Lima e Araújo (1999), sementes infectadas com o $F$. oxysporum geralmente se deterioram, apresentandose encharcadas e podres. Também quando associado às sementes pode infectar raízes, ramos, ginóforos e vagens (MORAES; GODOY, 1997).

Cercospora arachidicola, em condições de préemergência, causou podridão e redução de $42 \%$ na germinação das sementes imersas. O mesmo quando inoculado por meio de contato direto das sementes com a colônia do fungo reduziu o percentual de germinação em cerca de $13 \%$. Na pós-emergência, na avaliação aos 15 dias após a inoculação, as plântulas apresentavam lesões marrons no caule. Nas plântulas severamente afetadas, cerca de 70,58\% (Figura 3), foi observado sintoma de murcha e posteriormente morte destas. Lima e Araújo (1999) também conseguiram maior associação de $C$. arachidicola com as sementes por meio da imersão das mesmas em suspensão de conídios, antes da semeadura. A inoculação artificial pode assegurar a identificação precisa do fungo e é indispensável em trabalhos relacionados com a transmissão pelas sementes.

A patogenicidade de fungos inoculados sobre o desenvolvimento das plântulas foi evidenciada por meio da redução na altura e comprimento de raízes em comparação às testemunhas não inoculadas (Tabela 2). A maior redução em altura de plântulas foi observada para o A. niger. Para o comprimento de raízes, a maior redução foi observada em plântulas originadas a partir de sementes inoculadas por meio de imersão em suspensão de esporos de $C$. arachidicola. Sendo que os sinais da infecção tiveram início na raiz principal, próximo ao nível do solo, com os tecidos radiculares apresentando inicialmente coloração marrom claro e com posterior apodrecimento.

Tabela 2. Altura de plântulas e comprimento de raízes de amendoim cv. Tatu originadas de sementes inoculadas com fungos.

\begin{tabular}{llc}
\hline \hline \multirow{2}{*}{ Fungos inoculados nas sementes } & \multicolumn{2}{c}{ Desenvolvimento de plântulas } \\
\cline { 2 - 3 } & \multicolumn{1}{c}{$\begin{array}{c}\text { Altura de pântulas } \\
(\mathrm{cm})\end{array}$} & $\begin{array}{c}\text { Comprimento de raízes } \\
(\mathrm{cm})\end{array}$ \\
\hline Aspergillus niger & $07,92 \mathrm{c}^{1}$ & $03,60 \mathrm{~b}$ \\
Fusarium oxysporum & $12,92 \mathrm{~b}$ & $03,12 \mathrm{~b}$ \\
Cercospora arachidicola imersão & $10,92 \mathrm{bc}$ & $00,45 \mathrm{c}$ \\
Cercospora arachidicola deposição & $11,21 \mathrm{bc}$ & $03,73 \mathrm{~b}$ \\
Testemunha & $22,09 \mathrm{a}$ & $11,45 \mathrm{a}$ \\
\hline CV $(\%)$ & 29,11 & 27,33 \\
\hline \hline
\end{tabular}

${ }^{1}$ Médias seguidas de mesma letra, na coluna, não diferem entre si pelo teste de Tukey a 5\% de probabilidade.

Os resultados obtidos no experimento mostraram que os fungos $A$. niger, $F$. oxysporum e $C$. arachidicola, quando associados às sementes de amendoim, podem causar tombamento na pré e pósemergência. O A. niger e o $F$. oxysporum foram mais agressivos quando inoculados nas sementes, reduzindo drasticamente o percentual de germinação e o $C$. arachidicola na pós-emergência, com maior percentual de plântulas doentes.

\section{Referências}

ARAÚJO, A. E. S.; ROSSETTO, C. A. V. Efeito do hipoclorito de sódio no desenvolvimento de fungos em teste de sanidade de sementes de Arachis hypogaea L. Informativo Abrates, v. 13, n. 3, p. 232, 2003.

BRASIL. Ministério de Agricultura e Reforma Agrária. Regras para análise de sementes. Brasília, 1992. 365 p.

COOK, A. A. Diseases of tropical and subtropical field, fiber and oil plants. New York: MacMillan, 1981.450 p. 
GIBSON, I. A. S. Crown rot, a seedling disease of groundnuts caused by Aspergillus niger. Transactions / British Mycological Society, Cambridge, v. 36, p. 198-209, 1953.

GODOY, I. J.; MORAES, S. A.; ZANOTTO, M. D.; SANTOS, R. C. Melhoramento do amendoim. In: BORÉM, A. (Ed.). Melhoramento de espécies cultivadas. Viçosa: UFV, 1999. p.51-94.

HANLIN, R. T. The distribution of peanut fungi in the Southeastern United States. Mycopathologia et Mycologia Applicata, Den Haag, v. 49, p. 243-277, 1973.

JACKSON, C. R. Aspergillus crown rot of peanut in Georgia. Plant Disease Reporter, Washington, v. 46, p. 888-892, 1962.

JOFFE, A. Z. The mycoflora of fresh and stored groundnut kernels in Israel. Mycopathologia et Mycologia Applicata, Den Haag, v. 39, p. 255-264, 1969.

KRAPOVICKAS, A.; GREGORY, W. C. Taxonomy of the genus Arachis (Leguminosae). Bonplandia, Corrientes, v. 8, n. 1-4, p. 1-186, 1994.

LIMA, E. F.; ARAÚJO, A. E. Fungos causadores de tombamento, transportados e transmitidos através da semente de amendoim. Revista Oleaginosas e Fibrosas, Campina Grande, v. 3, n. 2, p. 71-76. 1999.

MORAES, S. A. Ocorrência da podridão do colo em amendoim (Arachis hypogaea L.) causada por Aspergillus niger Van Tiegh., no Estado de São Paulo. Ecossistema, Espirito Santo Do Pinhal, v. 4, p. 123-126, 1979.

MORAES, S. A. Ocorrência da podridão do colo em amendoim (Arachis hypogaea L.) causada por Aspergillus niger Van Tiegh. Ecossistema, Espirito Santo Do Pinhal, v. 5, p. 115-124, 1980.
MORAES, S. A.; GODOY, I. J. Amendoim (Arachis hypogaea L.): controle de doenças. In: VALE, F. X. R.; ZAMBOLIM, L., (eds.) Controle de doenças de plantas: grandes culturas. Viçosa, UFV, 1997, p. 1-49.

MORAES, S. A.; GODOY, I. J.; GERIN, M. A. N.; PEDRO JÚNIOR, M. J.; PEREIRA, J. C. V. N. A. Epidemiologia de Cercosporidium personatum em genótipos de amendoim. Fitopatologia Brasileira, Brasília, v. 13, p. 255-260, 1988.

MORAES, S. A.; GODOY, I. J.; MARTINS, A. L. M.; PEREIRA, J. C. V. N. A.; PEDRO JÚNIOR, M. J. Epidemiologia da mancha-preta (Cercosporidium personatum) em amendoim: resistência, controle químico e progresso da doença. Fitopatologia Brasileira, Brasília, v. 19, n. 4, p. 532-540, 1994.

MORAES, S. A.; MARIOTTO, P. R. Diagnóstico da patologia de sementes de amendoim no Brasil. Revista Brasileira de Sementes, Brasília, v. 7, n. 1, p. 41-43, 1985.

NAKAMURA, K.; NISHIMURA, A. M. Fungos associados à má germinação de sementes de amendoim. Científica, São Paulo, v. 2, p. 257, 1974.

NEERGAARD, P. Seed Pathology. London: MacMillan, $1979.839 \mathrm{p}$.

SOARES, J. J.; LIMA, E. F. Avaliação da resistência de cultivares de amendoim às Cercosporioses. Campina Grande: EMBRAPA-CNPA, 1991. 12 p. (EMBRAPA-CNPA. Boletim de Pesquisa, 25).

WEISS, E. A. Oillseed Crops. London: Longman, 1983. $660 \mathrm{p}$. 